attained DAS-28 LDA at least once up to one year was 67 (92\%, 80\% to 97\%) and the number of patients attaining DAS-28 and Boolean remission were $31(50 \%, 34 \%$ to $61 \%)$ and $12(20 \%, 9 \%$ to $30 \%)$ respectively. Median time to DAS-28 LDA was 16 weeks (Figure 1). Cox regression analyses did not show any sufficiently precise association of remission or LDA with age, gender, seropositivity, disease duration, concomitant DMARD use and number of previous bDMARDs. Increasing number of previous bDMARDs was associated with poor baricitinib survival $(\mathrm{HR}=1.5,95 \% \mathrm{Cl} 1.1$ to 2.2$)$ while this association was not robust to adjustment for baseline disease activity. Favorable changes were observed in tender and swollen joint counts, pain-VAS, patient and physician disease assessment scores, RAID, FACIT and the acute phase response.

Conclusion: In this prospective observational study, we observed high rates of LDA and DAS-28 remission and significant improvements in disease activity and patient reported outcome measurements over time.

References:

[1] Keystone EC, Taylor PC, Drescher E, Schlichting DE, Beattie SD, Berclaz PY, et al. Safety and efficacy of baricitinib at 24 weeks in patients with rheumatoid arthritis who have had an inadequate response to methotrexate. Annals of the rheumatic diseases. 2015 Feb;74(2):333-40.

[2] Genovese MC, Kremer J, Zamani O, Ludivico C, Krogulec M, Xie L, et al. Baricitinib in Patients with Refractory Rheumatoid Arthritis. The New England journal of medicine. 2016 Mar 31;374(13):1243-52.
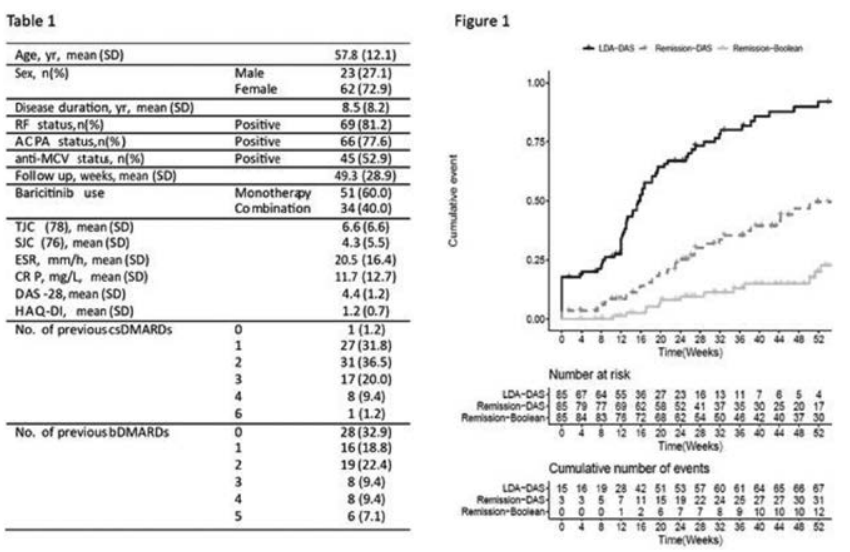

Figure 1. Cumulative probability of low disease activity or remission under treatment with baricitinib.

Disclosure of Interests: Sara Bayat Speakers bureau: Novartis, Koray Tascilar: None declared, Veronica Kaufmann: None declared, Arnd Kleyer Consultant of: Lilly, Gilead, Novartis,Abbvie, Speakers bureau: Novartis, Lilly, David Simon Grant/ research support from: Else Kröner-Memorial Scholarship, Novartis, Consultant of: Novartis, Lilly, Johannes Knitza Grant/research support from: Research Grant: Novartis, Fabian Hartmann: None declared, Susanne Adam: None declared, Axel Hueber Grant/research support from: Novartis, Lilly, Pfizer, EIT Health, EU-IMI, DFG, Universität Erlangen (EFI), Consultant of: Abbvie, BMS, Celgene, Gilead, GSK, Lilly, Novartis, Speakers bureau: GSK, Lilly, Novartis, Georg Schett Speakers bureau: AbbVie, BMS, Celgene, Janssen, Eli Lilly, Novartis, Roche and UCB DOI: 10.1136/annrheumdis-2020-eular.5263

\section{AB0331 EFFICACY, RETENTION RATE AND PREDICTORS OF TOFACITINIB EFFICACY AND RETENTION IN RHEUMATOID ARTHRITIS PATIENTS: HUR-BIO REAL- LIFE EXPERIENCE}

E. Bilgin ${ }^{1}$, F. Ceylan², E. C. Bolek ${ }^{1}$, E. Duran ${ }^{1}$, B. Farisoğulları ${ }^{1}$, G. K. Yardımcı ${ }^{1}$, L. Kılıç ${ }^{1}$, A. Akdoğan ${ }^{1}$, O. Karadag ${ }^{1}$, ş. A. Bilgen ${ }^{1}$, S. Kiraz ${ }^{1}$, A. I. Ertenli ${ }^{1}$, U. Kalyoncu ${ }^{1}{ }^{1}$ Hacettepe Üniversitesi Tıp Fakültesi, Internal Medicine, Rheumatology, Ankara, Turkey; ${ }^{2}$ Hacettepe Üniversitesi Tıp Fakültesi, Internal Medicine, Ankara, Turkey

Background: Tofacitinib (TOF) is an oral Janus Kinase (JAK) inhibitor and is indicated in the treatment of rheumatoid arthritis (RA). Several interventional or observational studies demonstrated its safety and efficacy, however, its real-life retention rate and related factors need to be elucidated further and its efficacy needs to be approved in real-life.

Objectives: To assess the real-life efficacy, retention rate and related factors of both parameter in rheumatoid arthritis patients under tofacitinib.

Methods: We analyzed all RA patients registered to HURBIO database who received at least 1 dose of tofacitinib (for drug retention) and who had at least 1 control visit under tofacitinib (for efficacy). Drug retention rates were calculated using the Kaplan-Meier method and predictors of drug retention were determined by Cox proportional hazard model. Patients were grouped as "responder" or "non-responders according" to DAS28 at last control visit: DAS28-CRP $\leq 3.2$ "Responders"; DAS28-CRP>3.2: "Non-responders". Predictors of response (DAS28-CRP $\leq 3.2$ at last visit) were determined by logistic regression analysis. Reasons for switching and discontinuation were also determined.

Results: For drug retention; a total of 247 (210 (85\%) female) patients were recruited. Mean age was $53.1 \pm 12.6$ years. Mean disease duration was $11.3 \pm 8.0$ years. Rheumatoid factor and anti-CCP antibodies were positive in 160/240 (66.7\%) and 135/207 (65.2\%) patients, respectively. Combination with DMARDs was used in $83.3 \%$ of patients. $55.5 \%$ of patients was biologic-naive. Median follow-up while receiving tofacitinib was 10.2 (IQR:4.0-24.2) months. One-year crude retention rate was $64 \%$. Median duration of drug retention was 24.8 months. Predictors of good tofacitinib retention were (in multivariate analysis): living in Ankara (where our center is located) (HR $1.43(0.96-2.14) ; 95 \% \mathrm{Cl}$ ) and $B M I>25$ (HR $1.46(0.97-2.29) ; 95 \% \mathrm{Cl})$

For efficacy; a total of 204 (174 (85.4\%) female) patients were recruited. Mean age was $53.2 \pm 12.5$ years. Mean disease duration was $11.5 \pm 8.1$ years. Rheumatoid factor and anti-CCP antibodies were positive in 135/198 (68.1\%) and 115/171 $(67.2 \%)$ patients, respectively. Detailed demographic and clinical characteristics of participants were given in table 1. Median follow-up while receiving tofacitinib was 11.6 (IQR:5.2-26.2) months. DAS28-CRP levels at baseline and last visit were 4.8 (IQR:3.9-5.4) and 3.3 (IQR:2.5-4.6), respectively $(\mathrm{p}<0.001)$. At last visit, $19.6 \%$ of patients was in low-disease activity (2.6 $\leq$ DAS28-CRP $\leq 3.2), 26.0 \%$ of patients was in remission (DAS28-CRP<2.6) Predictors of good response to tofacitinib were (in multivariate analysis, adjusted for follow-up duration under tofacitinib): biologic-navie (aOR 2.38 (1.30-4.34); 95\% Cl) and RF negativity (aOR 2.12 (1.13-3.95); 95\% Cl)

The most common cause of drug discontinuation was primary failure (in 36/108 patients, 33.4\%).

Conclusion: Tofacitinib seems an effective treatment option for rheumatoid arthritis Relationship between seronegativity and good response to tofacitinib needs to be elucidated. Also, Clinicians should keep in their mind that in addition to patient char acteristics, socioeconomic factors may influence the adherence to the treatment Disclosure of Interests: Emre Bilgin: None declared, Furkan Ceylan: None declared Ertugrul Cagri Bolek: None declared, Emine Duran: None declared, Bayram Farisoğulları: None declared, Gözde Kübra Yardımcı: None declared, Levent Kılıç: None declared, Ali Akdoğan: None declared, Omer Karadag: None declared, Şule Apras Bilgen: None declared, Sedat Kiraz: None declared, Ali İhsan Ertenli: None declared, Umut Kalyoncu Consultant of: Abbvie, Amgen, Janssen, Lilly, Novartis, UCB DOI: 10.1136/annrheumdis-2020-eular.788

\section{$\mathrm{AB} 0332$ IMMUNOSUPPRESSIVE AND IMMONOMODULATING AGENTS IN RHEUMATOID ARTHRITIS: A SYSTEMATIC REVIEW OF CLINICAL TRIALS AND THEIR CURRENT DEVELOPMENT STAGE}

J. Blaess $^{1}$, J. Walther ${ }^{2}$, J. E. Gottenberg ${ }^{1}$, J. Sibilia$^{1}$, L. Arnaud ${ }^{1}$, R. Felten ${ }^{1}$. ${ }^{1}$ Hôpitaux Universitaires de Strasbourg, Service de Rhumatologie, Strasbourg, France; ${ }^{2}$ Hopitaux Universitaires de Strasbourg, Service de pharmaciestérilisation, Strasbourg, France

Background: Rheumatoid arthritis (RA) is the most frequent chronic inflammatory diseases with an incidence of $0.5 \%$ to $1 \%$. Therapeutic arsenal of RA has continuously expanded in recent years with the recent therapeutic progress with the arrival of conventional synthetic disease-modifying anti-rheumatic drugs (csDMARDs), biological (bDMARDs) and targeted synthetic (tsDMARDs), JAK inhibitors. However, there are still some unmet needs for patients who do not achieve remission and who continue to worsen despite treatments. Of note, only approximately $40 \%$ of patients are ACR70 responders, in most randomized controlled trials. For these patients, finding new therapeutic avenues is challenging Objectives: The objective of our study was to analyze the whole pipeline of immunosuppressive and immunomodulating drugs evaluated in RA and describe their mechanisms of action and stage of clinical development.

Methods: We conducted a systematic review of all drug therapies in clinical development in RA in 17 databases of international clinical trials. Inclusion criterion: study from one of the databases using the keywords "Rheumatoid arthritis" (search date: June 1, 2019). Exclusion criteria: non-drug trials, trials not related to RA or duplicates. We also excluded dietary regimen or supplementations, cellular therapies, NSAIDs, glucorticoids or their derivatives and non-immunosuppressive or non-immunomodulating drugs. For each csDMARD, bDMARD and tsDMARD, we considered the study at the most advanced stage. For bDMARDs, we did not take into account biosimilars.

Results: The research identified 4652 trials, of which 242 for 243 molecules met the inclusion and exclusion criteria. The developed molecules belong to csDMARDs $(n=21)$, bDMARDs $(n=117)$, tsDMARDs $(n=105)$. 